\title{
Evaluation of Microwave Digestion Systems for Mercury Recovery in an Oil Matrix
}

by

M. J. Whitaker

Westinghouse Savannah River Company

Savannah River Site

Aiken, South Carolina 29808

J. W. Clvmire

This paper was prepared in connection with work done under the above contract number with the U. S. Department of Energy. By acceptance of this paper, the publisher and/or recipient acknowledges the U. S. Government's right to retain a nonexclusive, royalty-free license in and to any copyright covering this paper, along with the right to reproduce and to authorize others to reproduce all or part of the copyrighted paper. 


\section{DISCLAIMER}

This report was prepared as an account of work sponsored by an agency of the United States Government. Neither the United States Government nor any agency thereof, nor any of their employees, makes any warranty, express or implied, or assumes any legal liability or responsibility for the accuracy, completeness, or usefulness of any information, apparatus, product, or process disclosed, or represents that its use would not infringe privately owned rights. Reference herein to any specific commercial product, process, or service by trade name, trademark, manufacturer, or otherwise does not necessarily constitute or imply its endorsement, recommendation, or favoring by the United States Government or any agency thereof. The views and opinions of authors expressed herein do not necessarily state or reflect those of the United States Government or any agency thereof.

This report has been reproduced directly from the best available copy.

Available to DOE and DOE contractors from the Office of Scientific and Technical Information, P. O. Box 62, Oak Ridge, TN 37831; prices available from (423) 576-8401.

Available to the public from the National Technical Information Service, U. S. Department of Commerce, 5285 Port Royal Road, Springfield, VA 22161. 


\section{DISCLAIMER}

Portions of this document may be illegible electronic image products. Images are produced from the best available original document. 


\title{
EVALUATION OF MICROWAVE DIGESTION SYSTEMS FOR MERCURY RECOVERY IN AN OIL MATRIX
}

\author{
Joseph W. Clymire and Michael J. Whitaker
}

\section{INTRODUCTION}

The scope of this document is to characterize three microwave systems developed by CEM Corporation. The purpose of this investigative work was to evaluate the performance of each system for dissolution qualities and the recovery of mercury in an oil based matrix. The microwave systems evaluated were the heavy duty vessel system (HDV), the advanced composite system (ACV), and the open vessel system (OVS). All three systems have automated features, but all systems are limited by one factor or another. EPA method 3051 was the procedure used for sample preparation for this project. This particular microwave digestion method can also be used for other metal analytes of interest.

The microwave digestion technique, briefly described, involves combining a sample aliquot and reagents in a digestion vessel and placing the vessel in the microwave oven. The microwave equipment automatically monitors and controls key parameters such as time, temperature, and pressure so that the system can be run unattended. To digest the sample the microwave system utilizes elevated temperatures and pressures compared to the traditional water-bath and hot plate methods. This technique reduces the overall time to prepare a sample by digestion.

The objective of this project was to determine which system(s) could demonstrate a complete digestion of the oil based matrix and maintain a reasonably high per cent recovery for mercury. The analytical method development was performed at TNX with systems that were on temporary loan from CEM. The determination of the mercury concentration in each digested sample was by cold vapor atomic absorption. The instrument used was a Varian SpectrAA 800 with a vapor generation attachment. This flameless AA procedure is a physical method based on the absorption of radiation at $253.7 \mathrm{~nm}$ of mercury vapor. For total mercury results, it is necessary for a complete digestion to oxidize all inorganic and organic mercury into the appropriate ionic state. In a closed system the mercury ion is reduced to the elemental state by stannous chloride, which liberates the mercury as a nonionic gas. The solution is then aerated and the mercury vapor is swept through a special quartz cell positioned in the atomic absorption spectrometer. Absorbance of the mercury vapor passing through the path of light at $253.7 \mathrm{~nm}$ is measured as a function of concentration. 


\section{Method Development}

\section{CEM Heavy Duty Vessels (HDV) $\left(200^{\circ} \mathrm{C}, 600\right.$ PSI)}

The method development was performed with a MDS 2000 (650 Watt) microwave digestion system using the heavy duty vessels. A 0.5 gram oil sample was weighed into a HDV and 10 milliliters of nitric acid added. The vessel was then sealed and place in the microwave oven. The HDV can operate at a maximum reaction temperature of $200{ }^{\circ} \mathrm{C}$ and a maximum reaction pressure of 600 PSI. The temperature and pressure profile of an oil digestion performed with the HDV microwave system is shown below in figure 1. The maximum temperature for this particular run was $195^{\circ} \mathrm{C}$ and the maximum pressure was 575 PSI. The original digestion program for the HDV required holding the pressure at 200 PSI for five minutes. This higher pressure caused an unacceptable number of the rupture membranes to fail or for the entire vessel to "burp" at the Teflon liner and Teflon cap seal. For these reasons the temperature and pressure were lowered slightly from the rated maximum while the length of time remained at five minutes. A summary of the HDV program is shown below in table 1. The problem with burping HDV has been addressed by CEM. They have designed a new vessel known as the Ultimate Digestion Vessels (UDV) which has a maximum pressure of 1000 PSI. In the future the UDV will replace the HDV which will be discussed in more detail in the summary section of this document.

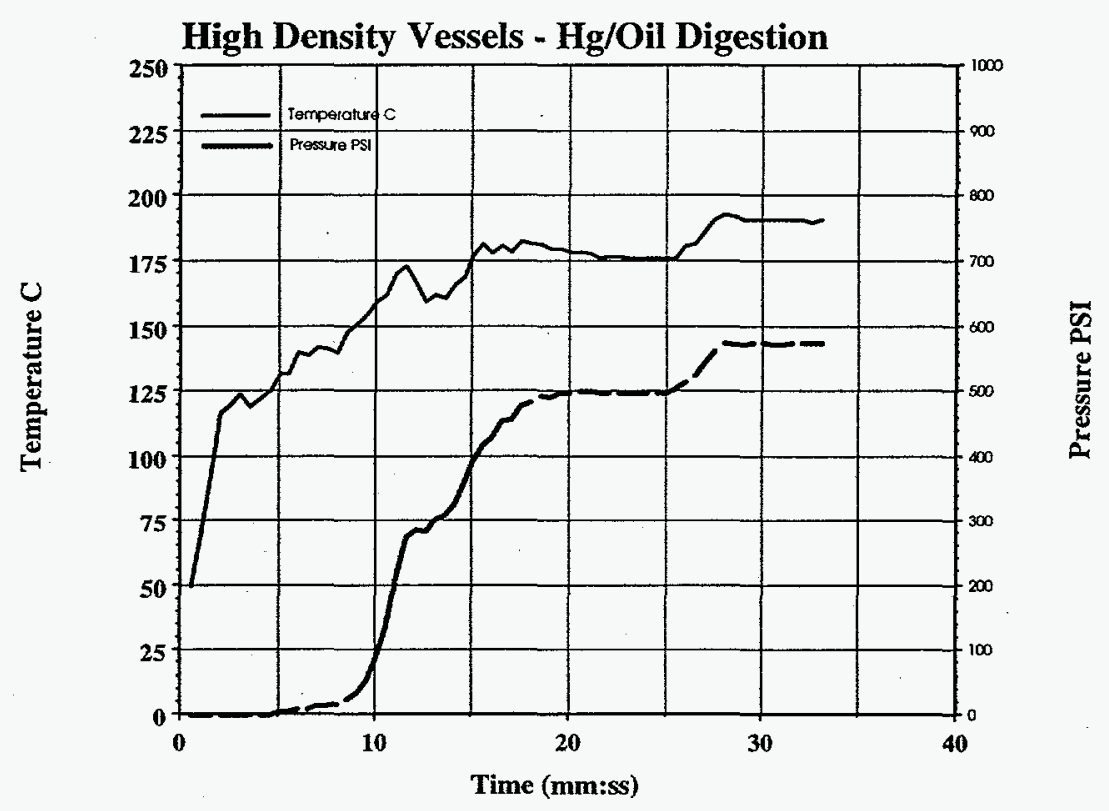

Figure 1 Oil digestion profile in high density vessels. 


\begin{tabular}{|c|c|c|c|c|c|}
\hline Stage & 1 & 2 & 3 & 4 & 5 \\
\hline \hline Power & $50 \%$ & $50 \%$ & $50 \%$ & $50 \%$ & $50 \%$ \\
\hline PSI. Max. & 100 & 200 & 400 & 500 & 575 \\
\hline Ramp Time & $2: 00$ & $2: 00$ & $2: 00$ & $2: 00$ & $5: 00$ \\
\hline Hold Time & $2: 00$ & $2: 00$ & $3: 00$ & $10: 00$ & $5: 00$ \\
\hline Max. Temp. & 120 & 140 & 160 & 180 & 195 \\
\hline
\end{tabular}

Table 1 Summary of high density vessel program.

The digested solutions were yellow and clear. When the dissolutions were diluted to volume they remained clear with no signs of precipitation. Due to the high temperature and pressure provided by the HDV system, it appears that all the organic compounds from the oil based matrix were completely oxidized. These digested HDV samples were analyzed by cold vapor atomic absorption. The calibration curve was based on mercury oil standards ranging from $5 \mathrm{mg} / \mathrm{g}$ to $105 \mathrm{mg} / \mathrm{g}$. The mercury recoveries were acceptable with an average recovery of $100.06 \%$ A summary of the results is shown below in table 2 .

\begin{tabular}{|c|c|c|c|c|c|}
\hline $\begin{array}{c}\text { Hg in Oil } \\
(\mu \mathrm{g} / \mathrm{g})\end{array}$ & $\begin{array}{c}\text { Time Between } \\
\text { Digestion and } \\
\text { Analysis }\end{array}$ & $\begin{array}{c}\text { Dilution } \\
\text { Factor }\end{array}$ & $\begin{array}{c}\text { Theoretical } \\
(\mu \mathrm{g} / \mathrm{L})\end{array}$ & $\begin{array}{c}\text { Analytical } \\
(\mu \mathrm{g} / \mathrm{L})\end{array}$ & $\begin{array}{c}\% \\
\text { Recovery }\end{array}$ \\
\hline \hline 81.5 & $0.5 \mathrm{hr}$. & 0.4209 & 34.3 & 34.3 & 99.8 \\
\hline 81.5 & $1.5 \mathrm{hrs}$. & 0.4209 & 34.3 & 34.9 & 101.6 \\
\hline 81.5 & $3 \mathrm{hrs}$. & 0.4209 & 34.3 & 32.6 & 95.1 \\
\hline 13.4 & $0.5 \mathrm{hr}$. & 2.7170 & 36.5 & 37.5 & 102.6 \\
\hline 13.4 & $1.5 \mathrm{hrs}$. & 2.7170 & 36.5 & 40.6 & 111.3 \\
\hline 13.4 & $3 \mathrm{hrs}$. & 2.7170 & 36.5 & 35.5 & 97.3 \\
\hline 40.3 & $0.5 \mathrm{hr}$. & 0.3986 & 16.1 & 16.6 & 102.9 \\
\hline 40.3 & $1.5 \mathrm{hrs}$. & 0.3986 & 16.1 & 16.0 & 99.4 \\
\hline 5.1 & $0.5 \mathrm{hr}$. & 1.0202 & 5.2 & 5.1 & 98.9 \\
\hline 5.1 & $1.5 \mathrm{hrs}$. & 1.0202 & 5.2 & 5.0 & 97.9 \\
\hline 102.6 & $0.5 \mathrm{hr}$. & 0.1002 & 10.3 & 10.0 & 97.7 \\
\hline 102.6 & $1.5 \mathrm{hrs}$. & 0.1002 & 10.3 & 9.9 & 96.2 \\
\hline
\end{tabular}

Table 2 Summary of mercury oil standards using high density vessels. 
To verify that no mercury was lost by absorption to the Teflon liners of the digestion vessels, nitric acid reagent blanks were digested between oil based matrix samples. All reagent blank results were less-than values. Combining this with the recovery data demonstrates there was no absorption of mercury into the Teflon liners. The recovery data shows there may be some evidence that the samples slowly degrade with time. This can be addresses by determining which sample container should be used for long time storage. In this work, the digested solutions were kept in glass volumetric flask. One is not sure if the mercury was being absorbed by the glass walls or was being lost through the glass stop cock over time. One requirement might be that the digestions be placed in a refrigerator prior to analysis. Further assessment of the overall holding times is an area that would need more investigation. By examining the results for the HDV, it is evident that the HDV gave excellent mercury recoveries. The HDV experiments suggest that this method is a viable preparatory step for cold-vapor mercury analysis on the oils examined.

\section{CEM Advanced Composite Vessels (ACV) $\left(200^{\circ} \mathrm{C}, 200\right.$ PSI)}

The method development was performed with a MDS 2000 (650 Watt) microwave digestion system using the advanced composite vessels (ACV). A $0.5 \mathrm{~g}$ oil sample was weighed into a ACV and 10 milliliters of nitric acid added. The vessel was then sealed and place in the microwave oven. The maximum reaction parameters for the ACV is a temperature of $200^{\circ} \mathrm{C}$ and a pressure of $200 \mathrm{PSI}$. The temperature and pressure profile of an oil digestion performed with the ACV microwave system is shown below in figure 2. The maximum temperature for this particular run was $160^{\circ} \mathrm{C}$ and the maximum pressure was $200 \mathrm{PSI}$. When the pressure reached $200 \mathrm{PSI}$, the temperature inside the vessels briefly reached a maximum temperature of $160^{\circ} \mathrm{C}$, then slowly began to decrease as the - pressure continued to rise. The data generated in the HDV experiments indicates that the oil based matrix does not fully break down until the temperature reaches $160-170{ }^{\circ} \mathrm{C}$ and maintains this temperature for a least 15 minutes. Therefore, the ACV system is temperature limited for a complete oil based matrix digestion to occur.

The ACV digested solution became cloudy when water was added, forming a white precipitate. This is a common phenomenon when the organic material has not been completely digested. An additional time consuming procedure utilizing potassium permanganate or potassium persulfate would be necessary in order to oxidize the organic material remaining in the incomplete digested solutions. Because of the additional steps to oxidize the organic material and the low mercury recoveries demonstrated from this method, the ACV system is not an acceptable alternative of digesting oil based matrix type samples. 
Advanced Composite Vessels - Hg/Oil Digestions

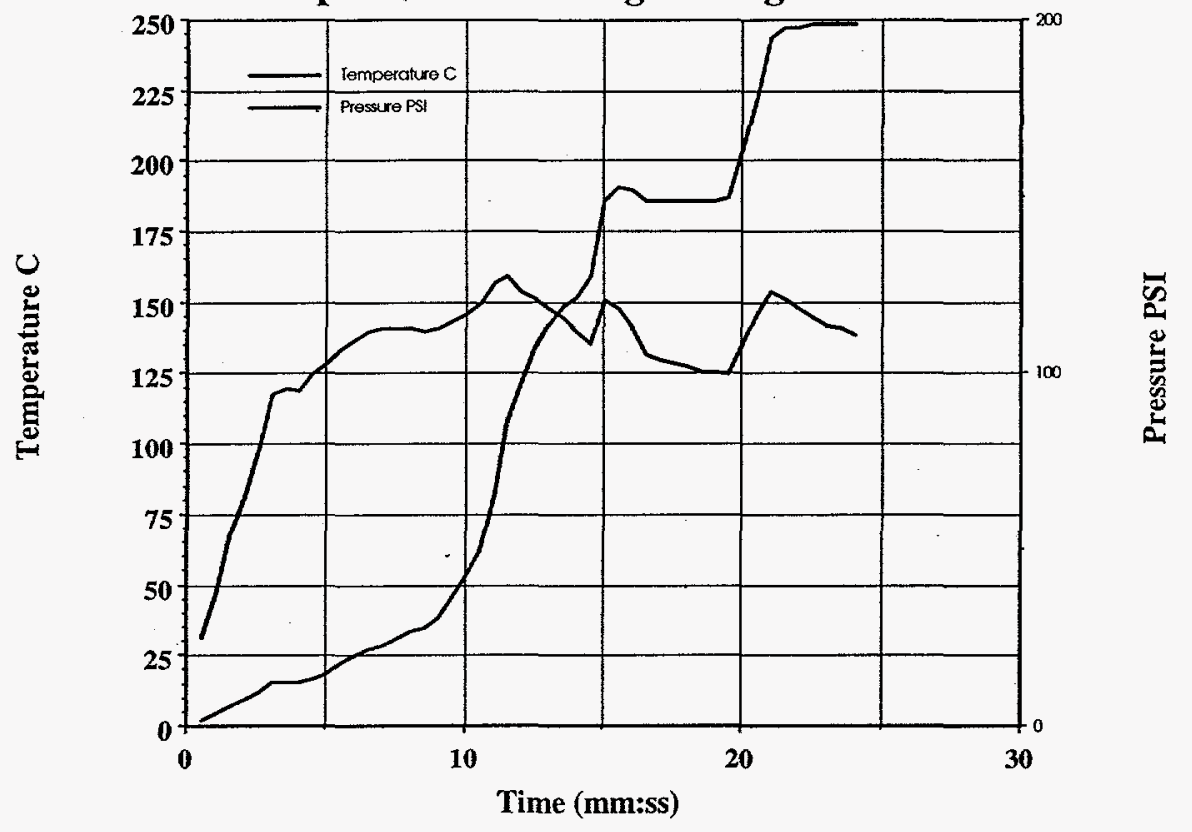

Figure 2 Oil digestion profile in advanced composite vessels.

\section{CEM Open Vessel System (OVS) (Star 2)}

CEM Corporation's Star System is their newest developed microwave digestion systems. This system is known as an open vessel system. The two previously discussed systems (HDV \& ACV) are considered close vessel systems. An open vessel system gives greater flexibility in sample size, 1 $\mathrm{g}$ to $10 \mathrm{~g}$ verses $0.25 \mathrm{~g}$ to $0.5 \mathrm{~g}$ for the closed vessel system. Two of the more important advantages to larger sample size are improve sample representation and increase mass (thus concentration) of element of interest. The open vessel system can be accommodated larger samples sizes because it is not pressure limited. For this particular project the key to developing a method to completely digest an oil based matrix is to slowly digest the oil without allowing the reaction to go exothermic. This means, to have the microwave control the reaction rather than the reaction running wild as the oil becomes oxidized.

Most of this development work for oils on the Star System was done in collaboration with Mike Moses, a senior application chemist from CEM. CEM has attempted to develop a method with the open vessel system for our particular needs, but the mercury recoveries are still not acceptable. The mercury recoveries were scattered and ranged from $28 \%$ to $75 \%$. A water cooled condenser was 
placed above the reaction vessel in order to improve the recoveries by decreasing the loss of volatile mercury.

For general method development purposes, 1.0 gram of oil, $5 \mathrm{~mL}$ of sulfuric acid, and $1 \mathrm{~mL}$ of nitric acid was places in the quartz vessel prior to beginning the digestion process. The Star System is fully automated and has the ability to add additional acids to the vessels during the digestion process. Table 3 below illustrates one of the routine programs that was created to digest the oil based matrix. After the temperature fell below $55^{\circ} \mathrm{C} 10 \mathrm{~mL}$ of potassium permanganate was added to the samples at the end of the digestion process to insure complete oxidation of the oil. After five minutes, $3 \mathrm{~mL}$ of hydroxylamine was added to reduce any excess permanganate present. The final dissolution was $100 \mathrm{~mL}$.

\begin{tabular}{|c|c|c|c|c|c|c|}
\hline Stage & $\begin{array}{c}\text { Ramp } \\
\text { Time }\end{array}$ & $\begin{array}{c}\text { Target } \\
\text { Temp }\end{array}$ & Hold Time & Reagent & Volume & Aliquot \\
\hline \hline 1 & $10: 00$ & $100^{\circ} \mathrm{C}$ & $10: 00$ & Nitric & $5 \mathrm{~mL}$ & $0.5 \mathrm{~mL}$ \\
\hline 2 & $10: 00$ & $120^{\circ} \mathrm{C}$ & $2: 00$ & Nitric & $1 \mathrm{~mL}$ & $0.5 \mathrm{~mL}$ \\
\hline 3 & $30: 00$ & $160^{\circ} \mathrm{C}$ & $10: 00$ & Nitric & $3 \mathrm{~mL}$ & $0.5 \mathrm{~mL}$ \\
\hline 4 & $30: 00$ & $170^{\circ} \mathrm{C}$ & $5: 00$ & $\mathrm{H}_{2} \mathrm{O}_{2}$ & $10 \mathrm{~mL}$ & $2 \mathrm{~mL}$ \\
\hline
\end{tabular}

Table 3 Summary of Star System digestion program.

The routine shown above in Table 3 appeared to be optimized and the reaction did not go exothermic. The temperature during the digestion was primarily controlled by the microwave rather than by the addition of additional nitric acid. It was determined from previous routines that adding larger aliquots of nitric acid during the digestion process would cause the Star System to wait for the temperature to drop before proceeding. The routine shown above in Table 3 gave a mercury recovery of $75.5 \%$.

It is the authors' opinion that mercury is to volatile of an element to work in an open vessel system where the oil matrix needs to be completely digested. In order to obtain $100 \%$ recoveries, the oil would have to be treated at lower temperatures. In this case, a microwave system would not be required. Subjecting a sample for several minutes to a water bath at $95^{\circ} \mathrm{C}$ might be sufficient with the addition of potassium permanganate to completely digest the oil. Based on the low recoveries demonstrated in this evaluation of the Star System, this system cannot be recommended for the complete digestion of an oil based matrix when mercury is the element of interest. 


\section{Summary and Recommendation}

Of the three different systems, only the HDV (now UDV) demonstrated complete digestion of the oil based matrix in a one step process and acceptable mercury recoveries. During the method development of the HDV, the controlling factor during the digestion process was the temperature. Even when the temperature reached $200^{\circ} \mathrm{C}$, the pressure usually reach a maximum of 550-580 PSI. Since the reaction is temperature dependent, a microwave system with a fiberoptic temperature controller is necessary. The temperature controlling limit for the UDVs is only $200^{\circ} \mathrm{C}$, primarily because of the Teflon inner liner. So it is possible to exceed the temperature limit of the vessel while maintaining a pressure well below the operating limits of 1000 PSI.

Another concern was is the power of the MDS 2000 microwave was sufficent. The MDS 2000 is $110 \mathrm{~V}, 650$ Watts microwave verses the MDS 2100 which is $220 \mathrm{~V}, 1000$ Watt microwave. It was determined in this evaluation that the MDS 2000 is not power limited in terms of driving the digestions. The MDS 2000 would be able to drive ten UDV, the maximum number of vessel per digestion run, without becoming limited by its 650 Watts of power. The MDS 2000 is an acceptable microwave digestion system for the complete digestion of the oil based matrices investigated. The cost of a complete system and necessary attachments and equipment is list below:

Microwave Sample Preparation System (MDS-2000)

$\$ 13,350.00$

(with fiberoptic temperature control option)

Ultimate Digestion Vessel Accessory Set (10 Vessels)

MDS-2000 Service Contract Plan II (24 months)

Upgrade from Glass Thermowell to PFA coated $\$ 30.00$

Accessories for the Future

Rupture Membranes for UDV (50/pk)

$\$ 18.00$

(Complete system $\$ 19,900$ ) 